\title{
O USO DO ORIGAMI NA APROPRIAÇÃO DA LÍNGUA INGLESA: PROJETO DE EXTENSÃO UNIVERSITÁRIA NA ILHA DE OUTEIRO - ESTADO DO PARÁ.
}

\author{
Leonardo Jovelino Almeida de LIMA \\ Universidade Federal do Pará \\ Jeová-Nisse Ramos MONTEIRO \\ Universidade Federal do Pará
}

\begin{abstract}
RESUMO: Considerando a necessidade de se aprender uma segunda língua nos dias atuais e os problemas que ocasionam a baixa qualidade no ensino do inglês nas escolas, principalmente nas escolas públicas, o docente deve enfatizar o processo de ensino/aprendizagem de uma língua estrangeira, utilizando estratégias/metodologias que envolvam a apropriação do conhecimento e o processo lúdico, atraindo assim mais a atenção do aprendente. Neste entendimento, o projeto de extensão universitária (Playful: Aprendendo o Inglês), realizado na comunidade do Fama, na ilha de Outeiro - Pará, objetiva o ensino do inglês para crianças e adolescentes carentes residentes no local, utilizando-se do processo lúdico, especificamente o Origami (tradicional arte japonesa que consiste em dobrar papel para adquirir formas de objetos, pessoas ou animais), como ferramenta facilitadora e motivadora. O projeto Playful empregou dinâmicas com o origami para o ensino/aprendizagem do inglês, levando em consideração, a cada aula realizada, as quatro habilidades necessárias da língua. Com base nas observações, percebeu-se: (a) uma maior motivação por parte dos alunos em buscar aprender a língua inglesa; (b) um significativo interesse pela autonomia; e (c) resultados mais satisfatórios nas habilidades da leitura (reading) e escrita (writing).
\end{abstract}

PALAVRAS- CHAVE: Projeto de Extensão; Língua Inglesa; Origami

\begin{abstract}
Considering the need to learn a second language nowadays and the problems that cause the low quality in the teaching of English in schools, especially in public schools, the teacher should emphasize the teaching and learning processes of a foreign language using strategies/methodologies that involve the appropriation of knowledge and the ludic process, thus attracting the attention of the learner. In this understanding, the project of university extension (Playful: Aprendendo o Inglês) realized in the community of the Fama, in the island of Outeiro - Pará, aims the teaching of English for children and teenagers who reside at the location, using the ludic process, specifically Origami (traditional Japanese art that consists of folding paper to acquire forms of objects, people or animals) as a facilitating and motivating tool. The Playful project employed origami dynamics to teach and learn English, taking into account, in each class, the four necessary skills of the language. Based on the observations, it was noticed: (a) a greater motivation on the part of the students to try to learn the English language; (b) a significant interest in autonomy; and (c) more satisfactory results in reading and writing skills.
\end{abstract}

KEYWORDS: Extension Project; English language; Origami.

\section{Introdução}

O projeto de extensão universitária 'PLAYFUL: APRENDENDO O INGLÊS', realizado na comunidade do Fama, na ilha de Outeiro - Pará, objetiva o ensino do inglês para crianças e adolescentes carentes residentes no local, utilizando-se do processo lúdico, especificamente o Origami (tradicional arte japonesa que consiste em dobrar papel para adquirir formas de objetos, pessoas ou animais), como ferramenta facilitadora e motivadora. 
Normalmente, o primeiro contato com o idioma ocorre nas escolas, onde os professores dispõem de poucas horas para trabalhar metodologias eficazes de ensino. Este fato faz com que o ensino/aprendizagem da língua inglesa seja inadequado, especialmente nas escolas públicas. Schmitz (2009) enfatiza esse problema quando anuncia que o número de horas para o ensino da língua estrangeira nas instituições públicas não é suficiente e não permite que o professor dê atenção a todas as habilidades: Listening (escuta), Writing (escrita), Reading (leitura), e Speaking (conversação).

Assim, o professor deve desenvolver novas metodologias de ensino, que incluam as quatro habilidades mencionadas. Neste processo, a competência dos educadores e suas capacidades de organizar situações de aprendizagem e desenvolver diretrizes para o trabalho em equipe (KAUARK; MUNIZ, 2008) são de grande importância. O docente pode ter sucesso no processo de ensino/aprendizagem de uma língua estrangeira ao trabalhar com estratégias que envolvam a apropriação do conhecimento e o processo lúdico, atraindo assim mais a atenção do aprendente.

O professor, como peça fundamental, deve estar hábil para produzir novos meios que abranjam todas as competências linguísticas, novos métodos para se alcançar os resultados esperados e/ou novas estratégias para atingir todos os mecanismos que um aluno precisa ser capaz de exercer.

Nessa perspectiva, a criatividade é algo primordial que um educador precisa ter para elaborar e desempenhar o gênero. Kauark e Muniz (2008) rezam que, para o docente, o desafio agora é ser criativo na elaboração e no desempenho das aulas. É preciso criar um ambiente onde a rotina seja quebrada, dando lugar a criatividade humana através de condições e estímulos favoráveis.

O caminho mais usado e eficaz, que une criatividade e aprendizado, é a prática lúdica. De acordo com Mayer-Borba (2007, p. 35), na visão de Vygotsky: "o brincar é uma atividade humana criadora, na qual imaginação, fantasia e realidade interagem na produção de novas possibilidades de interpretação, de expressão e de ação pelas crianças [...]". Assim, o brincar é um processo psicológico que pode prover o desenvolvimento e o aprendizado.

É na atividade lúdica que a criança desperta sua imaginação e interage com o meio, dando lugar a interpretação e ao aprendizado. O ensino absorvido de maneira lúdica, segundo Carvalho et al (1992), ganha um aspecto significativo a afetivo no processo de desenvolvimento da inteligência da criança.

Para que o professor consiga envolver o processo lúdico em suas aulas, é importante que ele conheça sua turma, planeje e organize melhor suas tarefas, considerando as necessidades e interesses de seus alunos, oportunizando-lhes situações em que possam usar a língua criativamente. Este planejamento torna o trabalho do professor mais fácil, economiza tempo e permite saber o que é necessário ou dispensável (SANTOS, 2010).

Em síntese, conhecer os alunos significa ter a compressão de que cada aprendente apresenta características distintas e específicas. Em uma turma de educação infantil, por exemplo, o professor precisa entender que cada aluno tem necessidades únicas, que diferem das necessidades dos demais. Ter isso em mente pode contribuir eficazmente para o planejamento da aula e, com isso, para a motivação e interesse dos alunos. 
O adequado planejamento de uma aula de língua estrangeira (LE) permiti que o professor possa enfatizar o ensino da língua nos pontos realmente relevantes para o aprendizado pelas crianças. Lima (2008, p. 304) conclui em sua pesquisa que:

As atividades propostas pelo professor devem permitir que o aluno use a língua para se comunicar e interagir com os colegas, visando não apenas o aprendizado de um vocabulário específico, mas o contato com o insumo rico e relevante que favoreça a produção criativa das crianças.

Assim, considerando que o domínio da língua estrangeira não é a única qualificação esperada pelo professor, é exigível que o mesmo utilize em sala de aula atividades que incluam a língua em diferentes contextos, permitindo, portanto, não somente o conhecimento do vocabulário pelos alunos, mas também favorecendo a utilização da língua para a comunicação e interação com seus pares.

Diante dos aspectos mencionados, uma prática lúdica que pode contribuir para que o professor de língua estrangeira atinja seus objetivos em sala de aula é a arte do Origami. Nesta atividade, o simples ato de dobrar papel traz consigo: raciocínio, significado e comunicação. Para Genova (2008), o origami é uma maneira de se expressar. A manipulação do papel faz haver comunicação com os pares, além de valorizar o movimento das mãos, estimulando as articulações assim como o cérebro. Desta maneira, o professor reuniria fatores que o ajudariam na organização da aula dentro e promoveria aprendizado diante uma nova metodologia de ensino, onde os resultados seriam atingidos através do brincar.

Neste cenário, o projeto PLAYFUL empregou dinâmicas com o origami para o ensino/aprendizagem do inglês, levando em consideração, a cada aula realizada, as quatro habilidades necessárias supracitadas. Os resultados apresentados foram baseados em observações dos professores (universitários) durante as aulas, diante dos benefícios do uso do origami no ensino do inglês.

\section{PLAYFUL: Projeto de Extensão Universitária}

\subsection{Considerações iniciais}

O projeto "PLAYFUL: APRENDENDO O INGLÊS" atua na comunidade do Fama, localizada na ilha de Outeiro (Belém - Pará), e oferece o ensino da língua inglesa para crianças e adolescentes de 09 a 16 anos, residentes no local, através de atividades lúdicas, especificamente, pelo uso do origami (tradicional arte japonesa que consiste na dobradura de papel para obter formas identificáveis, de animais, pessoas ou objetos).

A idealização do projeto aconteceu em junho de 2015 por quatro estudantes universitários do terceiro semestre do curso de letras (língua inglesa) da Universidade Federal do Pará, como uma forma de colocar em prática as pesquisas e atividades realizadas durante a disciplina "Aprender a Aprender", ministrada pela professora Walkyria Magno (ocorrida no primeiro semestre do curso); sem desconsiderar o interesse em adquirir prática de docência e a contribuição para que jovens e adolescentes carentes tenham a oportunidade de aprender uma segunda língua. 
O início das atividades ocorreu no dia 15 agosto de 2015 com a participação de 31 alunos. Inicialmente, aproximadamente 50 pessoas (entre crianças e adolescentes) mostraramse interessados em participar das aulas. Diante deste cenário, os responsáveis pelo projeto decidiram efetuar uma seleção: elaborou-se uma ficha de inscrição, na qual, cada interessado informaria seus dados pessoais e escreveria, com mínimo de 7 (sete) linhas, seus reais interesses em participar do projeto e aprender o inglês; 50 (cinquenta) cópias foram distribuídas, sendo 31 devolvidas, quinze dias após. Considerando que os responsáveis receberam de volta somente 31 fichas, definiu-se chamar todos estes para o início das aulas (com a possibilidade da divisão em duas turmas).

Neste primeiro dia de aula do projeto, decidiu-se não ministrar nenhum assunto referente à língua inglesa, sendo este dia dedicado somente à apresentação dos professores (universitários responsáveis) e exposição dos objetivos e metas do Projeto aos alunos. Os universitários responsáveis conversaram com cada aluno e perguntaram informações pessoais, como: nome, endereço, idade, série escolar, se já haviam entrado em contato com a língua inglesa e quais eram suas expectativas com a participação no projeto. Em resumo, obteve-se:

- Todos os alunos, sem exceção, informaram que frequentam escola pública e são residentes de Outeiro (Belém - Pará);

- A série escolar dos alunos varia desde $3^{\circ}$ ano ensino fundamental até o $1^{\circ}$ ano do ensino médio;

- Quanto a questão do contato com a língua inglesa, a maioria anunciou que este ocorreu (e ocorre) somente nas aulas de inglês na escola pública e que, mesmo assim, não considera as aulas rentáveis: quando o professor não faltava, as aulas eram somente voltadas para o verbo "To Be". Quando questionados o que o verbo "To Be" significava, somente uma aluna soube responder (ser ou estar), entretanto ela não sabia quando deveria utilizá-lo;

- As expectativas com a participação do projeto anunciadas pelos alunos foram pontos que levantaram bastante interesse dos universitários responsáveis, uma vez que variaram desde "obter boas notas em inglês na escola", "poder entender músicas e filmes em inglês" até "querer aprender a língua para viajar para outros países".

\subsection{Origami e o processo lúdico}

A utilização do origami pode contribuir significativamente para o sucesso de novas metodologias de ensino dentro da sala de aula, uma vez que permite associar a aprendizagem de uma língua estrangeira, especificando aqui o inglês, e o processo lúdico. Entretanto, antes de explanarmos o origami como ferramenta no ensino e aprendizagem de inglês no projeto "Playful: Aprendendo o Inglês", algumas explicações são necessárias.

O que é o Origami?

O origami (de ori, que significa 'dobrar', e kami que significa 'papel') corresponde a uma arte tradicionalmente japonesa de dobrar papel, que iniciou no século XVII e se popularizou fora do Japão em meados de 1900. O objetivo desta arte consiste em transformar 
um simples pedaço de papel, que normalmente é um quadrado, em formas significáveis, como animais, objetos ou pessoas, através de dobraduras e sem a utilização de cola ou tesoura.

Genova (2008), em seu livro "Origami: a milenar arte das dobraduras", explica que a arte de dobrar papel teve origem na China, entretanto, por não se popularizar neste país, ganhou ênfase no Japão, onde passou a ser chamada de origami, convertendo-se em uma prática muito popular e sendo considerada hoje patrimônio cultural do país.

O autor expõe também que, assim como no Japão, o origami na Europa era praticado principalmente por crianças, e que por isso, o pedagogo Friedrich Froebel ${ }^{1}$ percebeu rapidamente a possibilidade de educar brincando com dobraduras em papel entre outros materiais (GENOVA, 2008). E por esse motivo, muitas dobraduras geométricas trabalhadas nos jardins de infância por Froebel foram posteriormente chamadas de "froebelianas".

O divertido ato de dobrar papel pode significar um simples passatempo. Entretanto, se utilizado de forma correta, pode significar muito mais. O origami pode "abrir as portas de um universo onde estão presentes a arte, a ciência, a disciplina, a religiosidade, entre outros" (GENOVA, 2008, p. 11). Em sala de aula, basta o professor ter a criatividade e motivação para criar metodologias de ensino, e utilizar as dobraduras para chamar a atenção do aluno e incentivá-los a aprender e buscar cada vez mais o conhecimento, principalmente nas aulas voltadas para a aprendizagem de uma língua estrangeira.

\subsection{Uso do origami no ensino do inglês}

Demonstra-se neste tópico como os universitários responsáveis pelo projeto Playful: Aprendendo o Inglês utilizaram o origami como atividade lúdica no ensino e aprendizagem da língua inglesa, considerando as quatro competências requeridas: Listening (escuta), Writing (escrita), Reading (leitura), e Speaking (conversação).

\section{a) Listening (Escuta)}

Santos (2010) afirma que é aconselhável que o professor utilize, sempre que possível, a língua-alvo com o aprendiz, além de outras importantes ferramentas como figuras, fotos, formas, etc., na intenção de ocorrer a familiarização com os sons da nova língua. Neste sentindo, a competência do Listening foi praticada dentro de sala de aula através das explicações dos universitários responsáveis (professores) sobre como um origami podia ser criado e o aluno pôde associar as instruções ouvidas com a ação correspondente, permitindo assim que ele pudesse inferir o significado de palavras ou sentenças.

O uso da internet também foi importante, uma vez que os professores puderam levar para a sala de aula áudios e vídeos que ensinavam vários tipos de dobras, formas e origamis (pessoas, animais ou objetos), permitindo assim que os alunos pudessem também entrar em contato com a língua inglesa falada por um nativo. Esta atividade requereu que os professores tivessem o conhecimento necessário para se utilizar das contribuições provenientes dos

\footnotetext{
${ }^{1}$ Friedrich Wilhelm August Fröbel (1782-1852) foi um pedagogo e pedagogista alemão com raízes na escola Pestalozzi. Froebel foi o fundador do primeiro jardim de infância e o primeiro educador a utilizar o brinquedo, como atividade, nas escolas.
} 
computadores e da internet, entretanto, Ramos (2007) explica que este conhecimento não é o avançado, basta o docente ter uma atitude positiva em relação à essas novas tecnologias e entender os benefícios referentes a utilização do computador, como: atividades voltadas para especificamente para o ensino de LE, trabalhos interdisciplinares e a possiblidade de comunicação entre crianças de diferentes países.

Depois do origami já pronto, os professores se utilizaram de brincadeiras e jogos. Um bom exemplo do uso desses jogos com o origami associados à competência do listening foi a realização o jogo de adivinhações, no qual: a) os professores escolheram secretamente um origami feito por um aluno; b) os professores falavam as características em inglês desse origami escolhido; e c) os alunos tinham que tentar adivinhar de quem era o origami, com base as informações ouvidas dos professores. Para que esta atividade atingisse seu objetivo, os professores tiveram que utilizar ao máximo a língua inglesa em sala de aula, além de estipularem regras para jogo, repassando-as claramente aos alunos, informando assim quais as consequências caso elas não fossem seguidas. Quanto mais diversificados eram os origamis, quanto as formas, aos tamanhos e as cores, mais divertida e desafiadora era a dinâmica.

\section{b) Writing (Escrita)}

A competência do Writing (escrita) pôde também ser praticada com os alunos, pois elas puderam finalizar seus origamis ou criar suas próprias formas, escrevendo após pequenas histórias e/ou peças teatrais, com ajuda dos professores. Quanto a utilização da escrita, Santos (2010, p. 441) explica que ela permite "expressar personalidade, consolidar a aprendizagem em outras áreas, auxiliar na memória e desenvolvimento consciente da língua". Logo, os trabalhos com o origami associados à competência em questão contribuíram para que as crianças aprendessem estruturas gramaticais e novos vocabulários; além de permitirem que elas pudessem se expressar través das palavras.

$\mathrm{Na}$ criação de suas próprias formas, os professores pediram para que os alunos escrevessem (registrassem) em inglês, com ajuda, o passo a passo de como os origamis foram elaborados; ao final da aula, esses origamis foram expostos para todos na turma. É importante que a sala de aula possa oferecer um espaço para as exposições dos trabalhos produzidos pelos aprendizes, pois, eles podem sentir orgulho e interesse pelo que puderam construir ao longo da aula (SANTOS, 2010). Nas aulas do projeto, coube aos professores o estabelecimento deste espaço para exposições dos origamis; os professores também conversaram com os alunos sobre como ocorreu o andamento e a elaboração dos origamis e elogiaram os trabalhos feitos, como uma forma de motivá-los.

Outra atividade envolvendo a competência do writing foi considerada relevante para o atingimento dos objetivos do projeto: os professores levaram para a sala de aula 07 origamis (Pássaro Tsuru, Peixe, Canguru, Passarinho, Sapo, Cachorro e Gato), solicitaram que os alunos formassem grupos com três participantes; após, cada grupo teve que escolher um origami e, em um pedaço de papel, atribuir características pessoais a ele (como nome, idade, qualidades, aparência, etc.)

Foi notório pelos professores que alguns grupos estavam mais avançados que outros, uma vez que estes conseguiram elaborar textos e sentenças com mais palavras em inglês e, gramaticalmente, mais corretas. O uso do dicionário foi de grande importância para esta atividade. Os professores perceberam que muitos alunos deixavam de tirar suas dúvidas com eles (referente a palavras em inglês), para saná-las através do próprio dicionário. 
c) Reading (Leitura)

Santos (2010) afirma que uma boa técnica para se trabalhar o ensino da LE para crianças é a leitura de livros de histórias com muitas figuras, na qual o professor mostra as palavras e os desenhos e os alunos podem associar significados com símbolos escritos. Levando em consideração está técnica, os professores do projeto trabalharam com livros e apostilas sobre origamis com instruções em inglês, permitindo que os alunos pudessem fazer a inferência de significados através da agregação das imagens vistas com as palavras e/ou sentenças lidas, contribuindo assim para que a competência do reading fosse praticada.

Para a realização desta atividade, os professores levaram para a aula um diagrama (instruções) do origami de um sapo, escrito em inglês. No primeiro momento, os alunos tiverem 15 minutos para tentarem identificar, sem o uso do dicionário, as palavras em inglês que já conheciam ou entender as palavras cognatas (transparentes).

Após, os professores pediram para que os alunos tentassem elaborar, com ajuda, o origami do sapo, baseando-se nas instruções. A aula demorou um pouco mais que o planejado, uma vez que existiu a dificuldade de efetuar as dobraduras ou entender alguns comandos em inglês. Entretanto, alguns pontos satisfatórios puderam ser percebidos:

1. A compreensão de palavras e sentenças em inglês através da associação da imagem com os comandos (instruções):

- Palavras como: dobrar (fold), meio (half), abrir (open), terminado (finished);

- Sentenças como: 'dobrar ao meio' (fold in half) e 'virar para outro lado' (turn over);

2. A utilização cada vez maior do dicionário, permitindo que os alunos descobrissem sozinhos o significado de muitas palavras ou sentenças.

Os professores também pediram aos alunos que pesquisassem, em sala de aula ou em casa, novas formas de origamis (novos diagramas) em inglês, utilizando, para isso, livros, sites ou revistas. Essa atividade permitiu que eles aprendessem novas palavras, frases ou expressões, aumentando assim seu vocabulário na língua alvo. Foi solicitado também que os alunos levassem essas novas formas e/ou as novas palavras ou sentenças que aprenderam para a sala de aula na intenção compartilharem com os demais.

\section{d) Speaking (Conversação)}

Todo o trabalho em sala de aula realizado através da utilização do origami com as três competências descritas anteriormente pôde ser complementado com o incentivo a comunicação oral. Como exemplo, as crianças puderam divulgar para a classe as histórias e peças de teatro por elas criadas no momento da competência da escrita (writing).

Os alunos também apresentaram os origamis criados para seus colegas de classe. Para isso, os professores pediram para que cada grupo (com três participantes) apresentasse seu origami para os demais, informando as características atribuídas e os dados pessoais fictícios (nome, endereço, telefone, etc.). Neste dia, os professores optaram por avaliar a pronúncia de cada aluno, percebendo tanto, resultados satisfatórios para alguns e dificuldades para outros. Essas apresentações, que contaram com a ajuda dos professores, exigiram de um vocabulário próximo da realidade dos alunos; assim, os origamis contribuíram eficazmente para isso, uma 
vez eles permitiram que os aprendizes falassem sobre cores, animais, números, formas, ou até mesmo características pessoais ou emocionais (nomes, endereços, sentimentos, etc.).

Neste momento, o professor adquire um papel importante para o desenvolvimento desta competência, dado que ele deve estimular os seus alunos com tópicos que sejam interessantes e motivadores, para que os mesmos não fiquem frustrados ou envergonhados diante da exposição; além de servir como amparo linguístico (SANTOS, 2010).

\section{Considerações finais}

Este projeto mostrou que a arte do origami pode ser trabalhada em sala de aula e praticada no ensino/aprendizagem da língua inglesa; basta o professor ter a qualificação necessária e a iniciativa para criar novos métodos de ensino e abordagem, que envolvam, principalmente, o processo lúdico.

O projeto 'Playful: Aprendendo o Inglês' utilizou atividades com o origami para o ensino do inglês, levando em consideração, a cada aula realizada, as quatro habilidades necessárias da língua: Listening (escuta), Writing (escrita), Reading (leitura) e Speaking (conversação). Com base em observações, percebeu-se três pontos importantes:

(a) uma maior motivação por parte dos alunos em buscar aprender a língua inglesa: os professores/universitários entenderam que o uso do origami nas aulas de inglês contribuiu satisfatoriamente para a aprendizagem desta língua, ou seja, as aulas tornaram-se mais atrativas e proveitosas. Notou-se que os alunos se sentiam motivados para a aprendizagem, demonstrando assiduidade, um significativo interesse pelas atividades e diversos questionamentos para sanar dúvidas;

(b) um significativo interesse pela autonomia: o interesse dos alunos pelas atividades com o origami associadas ao ensino do inglês permitiu a prática de tarefas (sem ajuda ou solicitação dos professores/voluntários) fora do ambiente do projeto, como: pesquisas, em inglês, de novas dobraduras, novas formas, novas palavras ou sentenças, etc;

\section{(c) resultados mais satisfatórios nas habilidades da leitura (Reading) e escrita (Writing).}

Existem diversas maneiras que os professores podem utilizar o origami com seus alunos; as citadas neste trabalho corresponderam somente a uma pequena parcela. Os professores devem entender melhor e pesquisar cada vez mais sobre esta arte japonesa, e assim, elaborar novas metodologias de ensino, que chamem a atenção dos seus alunos e o incentivem a querer aprender a língua alvo.

É importante destacar que existem diversos origamis com diferentes níveis de dificuldades, logo, a utilização desta arte pode auxiliar o ensino/aprendizagem do inglês não somente com as crianças, mas também com jovens e adultos.

\section{Referências}


CARVALHO, A. M. A et al. Brincadeira e cultura: Viajando pelo Brasil que brinca. São Paulo: Casa do Psicólogo, 1992.

GENOVA, C. Origami: a milenar arte das dobraduras. $8^{\circ}$ edição. São Paulo: Escrituras Editora, 2008.

KAUARK, F.; MUNIZ, I. Motivação no ensino e na aprendizagem: competências e criatividade na prática pedagógica. Rio de Janeiro: Wak Editora, 2008.

LIMA, A.P. de. Ensino de língua estrangeira para crianças: o papel do professor. Cadernos de Pedagogia, v.2, n.3, p.293-305, jan./jul.2008. Disponível em: < ww.cadernosdapedagogia.ufscar.br/index.php/cp/article/view/48/41 >. Acesso em: 15.mai. 2016.

MEYER-BORBA, A. $O$ brincar como um modo de ser e estar no mundo. $2^{\circ}$ edição. Brasília: Ministério da educação, secretaria da educação básica, 2007.

RAMOS, S.G.M. A internet e suas contribuições ao ensino de inglês para crianças. In: TONELLI, J.R.A.; RAMOS, S.G.M. (org.). O ensino de LE para crianças: reflexões e contribuições. Londrina: Moriá, 2007. p. 61-76.

SANTOS, L.I.S. Ensino-aprendizagem de língua inglesa em anos iniciais do ensino fundamental: do planejamento ao alcance dos objetivos propostos. Linguagem \& Ensino, Pelotas, v.13, n.2, p.435-465, jul./dez.2010. Disponível em: < http://www.rle.ucpel.tche.br/index.php/rle/article/view/64> . Acesso em 15.mai.2016.

SCHMITZ, J. R. Ensino/Aprendizagem das quatro habilidades linguísticas na escola pública: uma meta alcançável?. In: LIMA, D. C. (org). Ensino e aprendizagem de língua inglesa: conversa com especialistas. São Paulo: Parábola Editoria, 2009. p.13 